\title{
40 Years of Innovation, Education and Intervention: Happy Birthday CVIR
}

\author{
Klaus A. Hausegger ${ }^{1}$
}

Published online: 7 August 2018

(C) Springer Science+Business Media, LLC, part of Springer Nature and the Cardiovascular and Interventional Radiological Society of Europe (CIRSE) 2018

Our journal turns 40 this year, which is more than a good reason to celebrate and reminisce. To commemorate the anniversary, we have summarised a selection of outstanding articles from the past four decades of CVIR. I hope you will enjoy browsing through our special anniversary issue.

\section{A Short Retrospection}

CVIR was founded in 1978 by professors, Herbert l. Abrams and Eberhard Zeitler. CVIR was listed in the Journal Citation Index (JCI) from its establishment and is the oldest international journal focusing on interventional radiology (IR). The international outspread was confirmed by the fact that regional editors from all regions of the world contributed with their voluntary support to the prosperity of the journal. Although the listing of CVIR in the JCI dates back later, the first information about an impact factor (IF) is available from 1997, being 0.865. Already two years later in 1999, the IF increased to 1.178. Since then, the IF increased steadily over the years, reaching 2.210 in the year 2017.

Eight Editors-in-Chief have served the journal, with a term of office between 4 to almost 14 years. Their enormous efforts and contributions were essential to the development and current position of the journal. Continuous submissions from our authors, the relentless and voluntary commitment of our Editorial Board members and our many reviewers as well as the vital support from the Editorial Office made CVIR, alongside with its American sister journal JVIR, the most important scientific journal covering all areas of IR today.

IR has made enormous progress during these 40 years and so has our journal. Currently, we receive more than 1000 manuscript submissions per year. Specifically, the year 2016 was a year of innovation for our journal—publication terms were changed from bimonthly to monthly, a new and improved online manuscript submission system was introduced, and new simplified guidelines for authors were designed.

CVIR is the official journal of the Cardiovascular and Interventional Society of Europe (CIRSE) and of many of our national and regional group member societies from around the world. This makes the journal a truly international platform for the exchange of science and education and is reflected by the global submissions it receives and the worldwide readership it serves.

Similar to interventional radiology being revolutionised over the years, publishing has also changed significantly. This process was driven by the distribution of the internet, beginning in the early 1990s of the last century. Online submission systems were introduced and helped to decrease manuscript turnaround times significantly. Articles have been made

Klaus A. Hausegger

CVIR.Hausegger@kabeg.at

1 Department of Diagnostic and Interventional Radiology, Klagenfurt State Hospital, Klagenfurt, Austria 
accessible online which, over time, made print journal more and more redundant. Today statistics of article downloads and online reading increases significantly with content being available on the reader's desktop, tablet or mobile phone. Searching for content online has outweighed the previous habit of sitting down in the evening and comfortably reading a print version of the journal on the sofa.

\section{A Look Ahead}

Today, online submission, reviewing and reading are fully integrated in the journal process and significantly accelerate the availability and searchability of articles. Also, CVIR will continue going fully digital with printed volumes only being sent out on special request and purchase of dedicated print subscriptions.

CVIR converting into a near to $100 \%$ online journal implies that our readers get electronic access to the articles. Members receive free electronic access through the CIRSE and CVIR websites as well as by using the CVIR app. Institutions make electronic access available to their readers through their online libraries. Regular electronic communication will notify readers when new articles and issues are available.

However, we need to recognise that the way to get access to medical journals content is further evolving. Traditionally, articles were accessible exclusively for subscribers of a respective journal, who paid a subscription fee. Or the access was provided by an institutional or public library. Today, the market is flooded with newly established open-access (OA) journals.

In contrary to subscription-based journals, like CVIR and many other renowned journals, OA scholarly journals offer unrestricted online access to their publications (so-called gold OA). Typically, OA journals charge their authors a publication fee, the so-called article processing charges (APCs) [1]. The ultimate goal of OA journals is to provide unlimited access to publicly funded research. This should help to disseminate available knowledge faster and also to a larger readership. Currently, clinicians and practitioners who are not affiliated to larger institutes, such as universities or other public institutions, which provide access to an online library, may be biased in knowledge finding when they limit their literature research to easily and free accessible OA articles. Moreover, the range of university-based online libraries is cost dependent. Therefore, if universities or other public institutions do not invest much money in such online libraries, the portfolio may be limited. All these points are good reasons to explain why OA journals are gaining increasing acceptance among scholars, as well as readers and authors.

In the meantime, a comprehensive index for OA journals, the "Directory of Open Access Journals" (DOAJ) has been introduced. Currently, 678 medical journals are listed in this index and 428,435 articles are available, according to the DOAJ website [2]. There is no doubt that there is competition between OA journals and traditional subscriber-based journals.

So-how will we publish in the future? Will everything be open access?

There are some concerns about the new OA trend. Of course, there may be concerns about the scientific quality of articles published in OA journals. OA journals may not follow the traditional peer-review process which is well established in traditional journals or may even introduce alternative review processes like open peer review or post-publication review. In addition, OA journals, which charge their authors an APC, may be tempted to accept articles of less quality just to keep their publication numbers and consequently their income high. So-called predatory journals have entered the field, whose primary interest is to receive publishing fees no matter of the quality of science they publish. However, the Directory of Open Access Journals acts to control such developments and provides a white list with trustworthy OA journals. The impact factor is no direct measurement of the scientific quality of a journal or paper; nevertheless, it is interesting to have a closer look on the development of the average impact factor in medicine and health publishing for OA journals and subscription-based journals. Until 2001, this average IF was significantly higher for the subscriber-based journals, whereas between the years 2002 and 2011, the values have become equal [3]. This means that OA journals are gaining increasing acceptance as well among readers and authors.

Other arguments against OA may be that publishers will lose subscribers and income. As a consequence, the scholarly publishing system, which currently to a large extent is maintained by publishers, may be weakened. Money may be transferred from research funding to funding in publishing, if scientists have to pay to get their research result published.

What does that all mean for our journal? I want to take the advantage of both worlds. Already now CVIR is a hybrid journal - today about $8 \%$ of our articles are open-access articles. The authors may decide whether their article should be set to free access, provided that they or their affiliating institution pay the open-access fee (so-called green open access). The percentage of open-access articles in our journal has not increased over the past years; however, this may change in future. 
On the other hand, I want to rely on the support and service of a powerful publisher like Springer and, of course, the CVIR Editorial Office in Vienna. We will maintain the well-established double-blinded peer-review process, which is timeconsuming for both the reviewers and the Editors; however, we are convinced that this is a guarantee for keeping the highest possible scientific quality.

As the Editor in Chief, I think that the combination of a traditional subscriber-based journal with a trend towards open access will meet the future requirements and will further contribute to the growth and impact of our journal.

\section{References}

1. Solomon DJ, Björk B-C. A study of open access journals using article processing charges. J Am Soc Info Sci Technol. 2012;63:1485-95. https://doi.org/10.1002/asi.22673.

2. https://doaj.org/search.

3. Björk BC, Solomon D. Open access versus subscription journals: a comparison of scientific impact. BMC Med. 2012;10:73. 